\title{
NO IMO DAS RELAÇÕES SOCIAIS: POSIÇÕES TEÓRICO-CONCEITUAIS SOBRE O INDIVÍDUO E A SUBJETIVIDADE.
}

\section{Sabrina Regina Fiorelli'; Dienifer Alexandra da Rosa Batista²; Marcela Lages dos Santos ${ }^{3}$; Félix Miguel Nascimento Guazina ${ }^{4}$}

\section{RESUMO}

Este artigo tem como objetivo apresentar o surgimento do indivíduo e sua subjetividade a partir de uma perspectiva histórica, de modo a salvar diferentes teorias e posições conceituais relacionadas à teoria social marxista e à pesquisa em serviço social. Trata-se de uma pesquisa, de cunho teórico-bibliográfica, que visa refletir criticamente sobre a área. Desta forma, é feita uma análise sócio-histórica, muito importante para incutir a subjetividade da composição individual e da dinâmica social capitalista. Além disso, busca sustentar a historicidade dos processos subjetivos aos olhos do serviço social e reconhecer a importância dos processos subjetivos no cotidiano do trabalho do assistente social.

Palavras-chave: Processos Subjetivos; Serviço Social; Trabalho Profissional.

Eixo Temático: Atenção Integral e Promoção à Saúde.

\section{INTRODUÇÃO}

Situar a temática da subjetividade e o indivíduo, resgatando os seus aspectos teórico-conceituais é de fundamental importância, especialmente se tratando de questão que perpassa pelo cotidiano profissional dos assistentes sociais. A pesquisa, proposta, de natureza teórico-bibliográfica, objetiva efetuar uma reflexão crítica sobre o assunto e, além disso, subsidiar uma avaliação sistemática das questões que envolvem o serviço social e o trabalho profissional no que tange à subjetividade.

Cabe salientar que há necessidade do reconhecimento dos processos subjetivos, como uma dimensão constitutiva dos indivíduos sociais e intrínseco aos processos que envolvem o trabalho profissional dos assistentes sociais no contato direto com o usuário. Portanto, é preciso compreender que, a subjetividade não pode ser reduzida a uma composição antagônica dos processos objetivos, mas sim,

\footnotetext{
1 Sabrina Regina Fiorelli - Universidade Franciscana (UFN) - fiiorelli@hotmail.com.

2 Dienifer Alexandra da Rosa Batista - Universidade Franciscana (UFN) - dienifer.batista@ufn.edu.br

3 Marcela Lages dos Santos - Universidade Franciscana (UFN) - marcelalages@gmail.com

4 Félix Miguel Nascimento Guazina - Universidade Franciscana (UFN) - felix@ufn.edu.br
} 
EDUCAÇÃO, SAÚDE

ETECNOLOGIA

26 A 28 DE OUTUBRO DE 2021

como uma unidade, engendradas pelas atuais configurações das relações sociais, imanente ao modo de produção capitalista.

A temática da subjetividade caminha em uma linha tênue entre o social e o "psico". Por isso, é necessário incentivar estudos e reflexões da prática profissional que subsidiem o seu reconhecimento, principalmente ao que tange o campo das relações sociais e dos processos que entrelaçam as questões de saúde e de doença, agravadas, pelas relações que se constroem na atualidade. Num contexto extremamente desigual, caracterizado pelo conservadorismo, controle e processos disciplinatórios.

Discutir a temática da subjetividade no serviço social passa pela compreensão do percurso trilhado pela profissão na construção da sua identidade. Para tanto é necessário elencar o que esse elemento significou no início da profissão e sua importância, apresentando um singelo recorte da institucionalização do serviço social no Brasil.

\section{DESENVOLVIMENTO}

Nos primórdios da institucionalização da profissão, a subjetividade era elemento principal de estudo e intervenção. No momento em que o serviço social quebra seus vínculos com a vocação atrelada aos desígnios da lgreja Católica, vêse obrigada a evidenciar sua eficácia e técnica para se equiparar às demais profissões, fundamentando-se, portanto, sob forte influência norte-americana e pelo pensamento positivista. Nesse ínterim, assume as características metodológicas de Caso, Grupo e Comunidade (ANDRADE, 2008).

A base metodológica de Caso, Grupo e Comunidade tinha a subjetividade como principal objeto de trabalho dos assistentes sociais, o ajuste dos indivíduos, dos grupos e das instituições. Para Silva (2008) essa tríade tinha como aporte a psicologização dos problemas sociais, portanto, pautava-se na personalidade do cliente como o objetivo de analisar sua personalidade e estimular mudanças no seu comportamento, e então, padronizá-los aos moldes da sociedade vigente.

Em uma outra direção, oposta àquela do período conservador, o que defendemos aqui é que a subjetividade seja utilizada pelo serviço social, de modo 
EDUCAÇÃO, SAÚDE

ETECNOLOGIA

26 A 28 DE OUTUBRO DE 2021

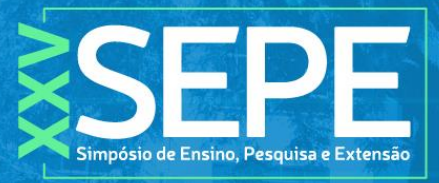

que constitua sua forma de atuação junto aos sujeitos sociais. Nesse ponto, a subjetividade, será trabalhada com o intuito de proporcionar uma visão crítica da realidade dos usuários e também permitir compreender a totalidade dos elementos que fazem parte dos processos sociais que envolvem esses sujeitos.

O autor Nicácio (2006) aponta que a recusa aos saberes "psi" no serviço social é determinada por dois fatores: a) retorno ao psicologismo; e, b) a ideia dicotômica da relação entre indivíduo e sociedade.

O temor ao retorno do psicologismo, manifestado no serviço social conservador, não deixa de ser legítimo, uma vez que está em jogo a própria identidade profissional. Porém, a questão estagnou no discurso dos profissionais e toda e qualquer ação passa por julgamentos e, então, sua prática é uma denúncia, enquanto isso, muitos apontam a subjetividade como emergência no cotidiano de sua ação profissional.

A crítica ao reformismo conservador dentro do serviço social é um fator preponderante. Este redirecionamento da profissão, diante do seu objeto, foi de fundamental importância para a reconstrução de seus fundamentos teóricometodológicos e princípios ético-políticos, porém segundo Nicácio (2006), não deixou de produzir alguns efeitos colaterais que merecem ser questionados.

Ao combater a pscicologização dos problemas sociais no processo de renovação, o serviço social rechaçou as reflexões sobre as experiências subjetivas dos indivíduos socialmente relacionados. O processo também conduziu a negação das dimensões psíquicas dos usuários, como se elas não fossem uma realidade, ou como se fosse algo secundário.

A ênfase em análises macroestruturais, exigido pelo processo histórico de renovação, deixou de lado a reflexão de algumas questões, que ao longo de tempo, foram emergindo como dificuldades. Um exemplo disso é o modo pelo qual os indivíduos lidam com a questão social e como essas refrações interferem na sua vida pessoal. Esse movimento configura e modifica as histórias de vida desses sujeitos; além de se tornar impasse quando confrontados também no cotidiano da prática profissional, no contato direto com os usuários das políticas. 
A possibilidade de uma contextualização a partir do pensamento de Marx sobre a subjetividade humana é particularmente pouco conhecida e carece de uma sistematização mais abrangente, tanto de estudos, quanto de interpretações. Por tanto, anunciar a emergência em tratar dessa temática é também gerar meios para que se possa ampliar o conhecimento sobre o assunto.

Numa perspectiva mais contemporânea, a subjetividade é o principal objeto de preocupação da coletânea de Eduardo Mourão Vasconcelos. A releitura às obras de Marx, por Vasconcelos ganha profícuas associações com a psicanálise, realizando reflexões acerca da subjetividade, num engajamento direto com os processos de reforma psiquiátrica e luta antimanicomial, bem como, dos movimentos de transformação societárias que configuram novas dimensões à assistência.

As reflexões, acerca da temática da subjetividade, não são exclusivas de Vasconcelos. Há evidências de outros teóricos marxistas que se esforçam para fazer emergir uma concepção atual de subjetividade, incentivando reconsiderações e sistematizações de aproximações da temática com a teoria social crítica de Marx. Esses movimentos visam encontrar elementos que subsidiem uma nova forma de pensar os sujeitos individuais, como decorrência das relações sociais, condicionados por suas determinações históricas, políticas e culturais. Ou seja, vislumbram um ser humano constituído para além da sua individualidade e do seu psiquismo.

Para Chagas (2013), Marx não entende a subjetividade como um mero reflexo das determinações econômicas, interpretada como produto econômico, mas sim, como um componente intrínseco à formação da vida humana. Portanto, para o autor, o pensamento de Marx não pode ser de maneira alguma reduzido a um objetivismo, ou a um determinismo econômico e de mão única. A objetividade não é concebida sem uma íntima correspondência à subjetividade, ou seja, não há para ele objeto sem sujeito e vice-versa.

Para Nicola Abbagnano (1998), a subjetividade corresponde ao que é aparente, ilusório ou falível, o que é intocável e corresponde somente ao indivíduo. Nesse sentido, o autor situa Hegel que conclui a esfera da subjetividade ao "deverse em geral", ou seja, corresponde aos interesses e as metas estabelecidas pela esfera subjetiva do indivíduo e ainda cita Kierkegaard para quem a subjetividade 
EDUCAÇÃO, SAÚDE

ETECNOLOGIA

26 A 28 DE OUTUBRO DE 2021

consiste em algo acima da objetividade, ou seja, o individual acima do universal. $\mathrm{O}$ subjetivo é a relação entre as coisas e o nós, ou seja, uma relação com quem as pensa, diferente do objetivo que é uma propriedade dos objetos. Por tanto, "o subjetivo é aquilo que pertence ao sujeito ou tem caráter de subjetividade" (ABBAGNANO, 1998, p. 922).

Em suma, o que é comum entre as diferentes formas de interpretações é de que existe um ser humano, antes de tudo, humano enquanto espécie biológica e que, socialmente relacionado, produz e reproduz expressões que dizem respeito a sua forma de ser e agir. Porém, o que difere Marx de outros pensadores, é produto de uma leitura que se apropria do modo de produção capitalista, cujos processos dizem respeito às transformações do modo de produzir que impactam no conjunto das relações sociais e, consequentemente, os indivíduos.

Marx, em "Manuscritos Econômico-filosóficos", "o homem não é um ser abstrato, acovardado, fora do mundo. O homem é o mundo do homem, o Estado, a coletividade" (MARX, 2001, p. 45). Nessa concepção, o indivíduo é um ser social consciente, que caminha em uma linha tênue entre o limite de sua naturalidade e os resultados de sua vida em sociedade. Portanto, não há, na sua natureza, algo que o crie de forma estanque ao meio, fixo e imutável, mas também há influências de suas relações sociais e de suas atividades vitais, frente as quais encontra formas de se autocriar e de se autoformar, por meio do trabalho.

Assim sendo, para Marx, as relações sociais são relações entre indivíduos humanos e a própria sociedade é produto dos mesmos. Deste modo, há uma ação recíproca de troca entre a sociedade e o indivíduo. Há também uma conexão imprescindível e que não deve ser negada, em que o indivíduo está vinculado diretamente às relações sociais e à sociedade que o produz, mas ao mesmo tempo, o indivíduo também a produz. Ou seja, o indivíduo não é só produto da sociedade, portanto, das relações sociais, mas é produto, ao mesmo tempo em que é produtor. Marx deixa isso claro ao escrever sua III Tese sobre Feuerbach, afirmando que:

A doutrina materialista segundo a qual os homens são produtos das circunstâncias e da educação e, portanto, segundo a qual os homens transformados são produtos de outras circunstâncias e de uma educação modificada, esquece que são precisamente os homens que transformam as 


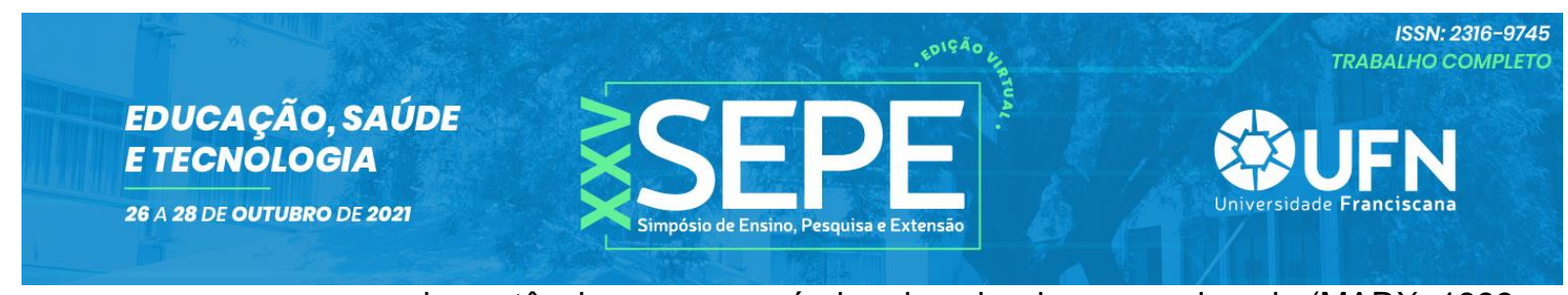

circunstâncias e que o próprio educador deve ser educado (MARX, 1888, p. 1).

Marx não vê, portanto, o indivíduo como um ser generalizado e individualizado fora da sociedade, mas enxerga-o na sua ligação com o social, dentro das relações sociais, como um exemplar determinado pelo social. Com isto, não se deve ver aqui a negação do indivíduo em Marx, pois as relações sociais são relações entre indivíduos. Assim sendo, na sociedade capitalista, tem-se um indivíduo condicionado por essa sociedade; e esse é o primeiro pressuposto que constitui as relações capitalistas. Daí a crítica de Marx e Engels ao autor Feuerbach, para quem o indivíduo é visto apenas como um ser isolado e abstrato. Para Marx "a essência humana não é uma abstração inerente ao indivíduo singular. Em sua efetividade, é o conjunto das relações sociais", diz ele na VI Tese sobre Feuerbach (MARX, 1888, p. 2).

Deste modo, o indivíduo não é somente um ser passivo de alterações do modo de vida material, há entre o indivíduo e a sociedade um produto que se dá em conjunto. O indivíduo não é um ser humano privado e estanque ao meio, ele é desde a matéria prima até o mais belo artefato já produzido.

O indivíduo para Marx é um indivíduo social e fruto das relações sociais, relações essas que, dentro de uma perspectiva do modo de produção capitalista, se tornam relações de mercado, mediadas por um valor de uso e de troca, ocasionando, o que Marx considera um esvaziamento dos indivíduos sociais e, por conseguinte, das relações humanas. O que antes unia os indivíduos através de laços sociais e culturais, são substituídos e subsidiados por laços mercantilizados, vindo de um mundo onde o capital produz a desumanização dos próprios indivíduos que o reproduzem.

Na obra "O Capital" (2011) Marx analisa o indivíduo dentro da sociedade capitalista e afirma que o ser, com relação ao modo de produção a que está submetido, é um mero agente de produção, reduzindo, portanto, seu significado a um caráter estritamente econômico, Nesse modo o indivíduo é apenas um portador de valor e agente mercantil. 
Dada as condições apresentadas pelo sistema capitalista, o dinheiro torna-se então um mediador dos processos que gerem a sociedade e, principalmente, das relações sociais, ou seja, tudo que envolve o indivíduo é analisado cautelosamente, onde até suas potencialidades e capacidades são medidas à maneira que seja mais financeiramente benéfica ao capital, passível de obter 0 maior lucro. Consequentemente, o dinheiro revela uma verdadeira potencialidade do indivíduo, pois sua posse significa poder e, este, está acima de suas capacidades laborais, naturais ou intelectuais (CHAGAS, 2013).

$\mathrm{Na}$ contemporaneidade, ao direcionarmos um olhar sobre a atualidade, nos damos conta da complexidade das relações que se estabelecem na vida em sociedade. Tal contexto, demanda uma atenção especial e minuciosa sobre as relações que envolvem o indivíduo e sua subjetividade. Nessa direção, pretendemos defender a existência de uma subjetividade e de uma objetividade, construídas ou constituídas, de um só sujeito, portanto, intrínsecas e inseparáveis ao indivíduo, ou seja, o âmago de sua existência.

Alguns autores percebem que a subjetividade está relacionada diretamente ao modo como do indivíduo se vê e percebe o mundo ao seu redor, como ele pensa, reflete, age e interage nas suas relações com a comunidade, que pode se manifestar de uma forma mais objetiva por meio de ações. Essa peculiaridade individual perpassa, desenvolve e processa como um todo a subjetividade humana.

O indivíduo aqui nunca pode aparecer isolado de forma tão clara como se fosse um mero trabalhador livre. Se as condições objetivas de seu trabalho são pressupostas como pertencentes a ele, ele mesmo está subjetivamente pressuposto como pertencente à comunidade, através da qual seu relacionamento com a terra é mediado (MARX; ENGELS, 1939, p. 409).

Nessa direção, Amatuzzi (1996) apontou que a subjetividade é o cerne mais profundo da experiência, sendo impossível conhecê-la objetivamente. Por outro lado, deve-se sempre lembrar que embora a subjetividade humana pertença ao âmbito de nosso universo interno, não é algo que constitui inatismo e internalidade, mas também o resultado de atividades desenvolvidas pela experiência humana nas relações de vida em sociedade. 
Este processo de aprendizagem inclui não apenas os pensamentos, emoções, sentimentos e transformações conscientes e inconscientes da área mais interna, mas também os produtos da interação mútua. Este processo é responsável também pela forma de observar o mundo e a própria vida, e é um elemento fundamental na formação e consolidação da identidade de cada um.

O comportamento humano se manifesta na representação, no ato de pensar e na sua produção como ser socialmente envolvido, ou seja, o universo do subjetivo humano não é apenas constituído de uma só história de vida, mas a essa também não se limita. As vivências perpassam por etapas de infinitas mudanças e se entende no percurso das vivências de todos os indivíduos que a compõe.

A autora Maheirie (2002) afirma que a subjetividade é uma dimensão do sujeito, assim como, a objetividade, que se constrói a partir das experiências tanto afetivas quanto reflexivas das relações que se estabelecem na vida em sociedade, capaz de produzir, não somente significados singulares, mas também coletivos. Essa afirmação é subsidiada a partir da necessidade de se compreender o homem e as suas relações sociais e apontar o significado da palavra identidade, para ela, sinônimo de subjetividade, sendo compreendida como uma dimensão do sujeito que, é acima de tudo um ser aberto e inacabado.

Quando trabalhamos sob a perspectiva do serviço social e sob a temática da subjetividade fica difícil limitar ou descrever um conceito que a defina. Porém, de qualquer forma, independente de estabelecer esse conceito, que possa ou não ser utilizado, entendemos que toda e qualquer concepção carrega consigo, implícita ou explicitamente uma ontologia que a sustenta. Ou seja, todas as teorias, trazem uma concepção genérica e geral que serve de horizonte para a fundamentação e desenvolvimento do que é ou do que seja a subjetividade.

Maheirie (2002) assegura, em seus escritos que não podemos reduzir o indivíduo a um corpo e uma consciência, separando a objetividade da subjetividade. O sujeito, o "eu" ou a "identidade", são também produtos das relações e que, sendo produto, existe uma objetividade e uma subjetividade efetivamente situadas no contexto social, ou seja, não se pode reduzir o indivíduo por duas dimensões distintas (objetividade e subjetividade), ou separá-lo em duas fatias, há entre essas 
duas dimensões uma ligação, uma constituição de um só ser, o ser humano constituído e relacionado socialmente.

Chagas (2013), quando Marx referiu-se à subjetividade elencou que ela não pertence a uma instância individual, própria, autônoma e independente, nem é classificada como um mero produto da estrutura socioeconômica, mas a visualiza como indivisível e essencial para o processo formativo individual. Ou seja, para Marx não há objeto sem sujeito, da mesma forma que não há sujeito sem objeto.

E ainda afirma,

Marx não considera o indivíduo humano apenas no seu caráter objetivo, determinado, mas em seu processo de autodeterminação. E é nesse processo de autoconstrução que se criam novas formas de objetivação, que possibilitam, por sua vez, novas formas de subjetivação (CHAGAS, 2013, p. 16).

Sob essa perspectiva, a subjetividade é apenas uma dimensão dos sujeitos, assim como a objetividade. Somente a partir das relações sociais vivenciadas pelos indivíduos, constroem experiências efetivas e reflexivas que podem vir a produzir significados tanto individuais quanto coletivos, ou seja, faz parte de um processo de construção dos sujeitos.

Todos os processos constituintes de construção dos sujeitos são realizados coletivamente, pois os indivíduos estão constantemente inseridos em diferentes singularidades que, por sua vez, entrelaçam-se umas às outras. Portanto, na mesma medida que o indivíduo compõe sua própria história, também é realizado por ela. "Por isso, produto e produtor simultaneamente", nas palavras de Maheirie (2002, p. 36).

Basicamente, o que define a essência do indivíduo está relacionada diretamente a forma como vive, produz e reproduz sua vida. Nas palavras de Marx (2001, p. 84), "no modo da atividade vital encontra-se o caráter inteiro da espécie, seu caráter genérico, e a atividade consciente livre é o caráter genérico do homem".

Assim, o ser social não é somente referenciado e constituído por uma determinada forma social, mas também é construto de seus modos de vida, portanto da vida social humana. E é por meio dessa vida social humana que se constroem as consciências, que por sua vez, são historicamente direcionadas por sua produção 
material, porém não de forma estanque e determinada. Isso porque não é só o meio material econômico que produz a vida, mas é também o envolvimento de outras esferas de reprodução e produção, desde bens materiais até os imateriais, portanto, compostos pela objetividade e pela subjetividade (CORDEIRO, 2018).

\section{CONCLUSÃO}

As transformações sociais, engendradas pelos movimentos do sistema capitalista, produzem, tanto efeitos nos indivíduos, moldando sua subjetividade, quanto são produzidas por esses mesmos sujeitos sociais. Portanto, numa relação dialética, entre objetividade e subjetividade; cíclica, no que se refere as transformações sociais, impulsionadas também pelos sujeitos que a compõe; e perdurável, enquanto existirem indivíduos produzidos e produtores à lógica do sistema capitalista

O resgate histórico-conceitual apresentou as principais concepções acerca do indivíduo e da subjetividade. Neste sentido, o indivíduo é a primeira instância do mundo concreto e real, o qual, possui não só necessidades naturais, mas também potencialidades, portanto, capaz de se autofabricar e de produzir condições para satisfazer suas próprias necessidades, daí a interpretação de indivíduo à teoria marxista.

Procuramos abranger diversas áreas de conhecimento que possibilitaram uma interpretação de que a subjetividade é uma dimensão do sujeito, assim como a objetividade e, entender que, a subjetividade não é apenas um reflexo das determinações econômicas, mas é também componente essencial da formação da vida humana. Portanto, não há constituição de um sujeito sem objeto, assim como não há objeto sem a ação de um sujeito.

A importância que a subjetividade tem hoje para o serviço social é condizente com as finalidades do atual projeto ético-político. Principalmente ao que tange a construção de uma nova ordem societária, haja vista que, no passado da profissão, os eixos que norteavam a temática da subjetividade, bem como suas finalidades eram irrelacionais com o que se pretende hoje.

$\mathrm{Na}$ atualidade, trabalhar com a subjetividade significa compreender a totalidade dos processos a que estão imbricados os indivíduos sociais, é de 
antemão, reconhecer que as duas dimensões tanto a subjetiva quanto a objetiva se realizam em conjunto. Ambas dizem respeito ao ser humano e, que, portanto, não há como negar a existência de uma sem a outra e, sim, construir alternativas dentro do serviço social que dinamizem esse processo de entendimento da totalidade envolvendo as duas dimensões.

Pensar na relação entre o existir humano, sua realidade mais específica, na experiência da subjetividade e luta por reconhecimento, remete-nos indiretamente a pensar na luta pelos direitos humanos e contra todas as formas de discriminação que precarizam os princípios de igualdade e de exercício da cidadania, elegido pela categoria profissional como princípios norteadores do Código de Ética. Neste sentido, fica evidente, ao que já foi citado anteriormente no decorrer deste trabalho, que ainda há muito o que avançar em diversos segmentos no que tange ao trabalho do assistente social com a subjetivação do usuário na saúde mental e em outras áreas.

O que está claro é a intenção de construção de uma nova forma de lidar com o sofrimento dos usuários, acolhendo e cuidando efetivamente desses indivíduos, além de incentivar um novo lugar para a diversidade, a diferença e o sofrimento, tendo em vista que, sob todas as condições, lidamos com seres humanos, e temos um compromisso ético de garantir que seus direitos sejam garantidos e preservados. Para tanto é necessário que continuemos em frente, na busca por alternativas que viabilizem esses processos de garantias frente a dinâmica social vigente, vislumbrando uma nova ordem societária, mais justa e igualitária.

\section{REFERÊNCIAS}

ABBAGNANO, N. Dicionário de Filosofia. São Paulo: Martins Fontes, 1998.

AMATUZZI, M. M. Apontamentos acerca da pesquisa fenomenológica. Estudos de Psicologia (Campinas), 13 (1), 1996.

ANDRADE, Maria Angela Rodrigues Alves de. O metodologismo e o desenvolvimentismo no Serviço Social brasileiro - 1947 a 1961. Franca/SP, Serviço Social \& Realidade, v. 17, n. 1, p. 268-299, 2008.

BERTOZZI E. A; FACCI, M. G. D. Subjetividade: uma análise pautada na Psicologia histórico-cultural. Belo Horizonte, MG: Revista de Psicologia, vol. 17, n. 1, 2011. 
CHAGAS, E. F. O pensamento de Marx sobre a subjetividade. Revista Dialectus, Ano 1, n. 2, jan./jun.2013, p. 14 - 32.

. O pensamento de Marx sobre a Subjetividade. Revista de

Filosofia, v. 36, n. 2, 2012, São Paulo. Disponível em: <

http://www2.marilia.unesp.br/revistas/index.php/transformacao/article/view/3099 >.

Acesso em: 24 ago. 2018.

CORDEIRO, L. F. As transformações do mundo do trabalho: a produção flexível e suas manifestações na subjetividade do trabalhador. Porto Alegre: Universidade Católica do Rio Grande do Sul (PUC-RS), 2018.

MAHEIRIE, K. Constituição do sujeito, subjetividade e identidade. São Paulo: Interações, v. 7, n. 13, jun. 2002. Disponível em: < http://pepsic.bvsalud.org/scielo.php?script=sci_arttext\&pid=S1413290720020001000 $03 \& \operatorname{lng}=$ pt\&nrm=iso $>$. Acessos em: 15 jun. 2018.

MARX, K. ENGELS, F. A Ideologia Alemã. Edição e tradução de domínio público: 1939

MARX, K. Manuscritos Econômico-filosóficos. Coleção a obra prima de cada autor. São Paulo: Editora Martin Claret, 2001.

MARX, K. XXI Teses sobre Feuerbach. Edição e tradução de domínio público: 1888.

NICÁCIO, E. M. Serviço Social e subjetividade. Praia Vermelha - Estudos de Política e Teoria Social, Rio de Janeiro, n. 18, 2006.

SILVA, J. F. S. da. Serviço social e contemporaneidade: afirmação de direitos e emancipação política? Revista Ciências Humanas, UNITAU, v. 1, n. 2, 2008.social na atualidade. In: CFESS/CRESS Atribuições do serviço social. Distrito Federal

VASCONCELOS, E. M. Karl Marx e a subjetividade humana: a trajetória das ideias e conceitos nos textos teóricos. São Paulo: Editora Hucitec, 2010, vol. 1.

Saúde Mental e Serviço Social: o desafio da subjetividade e da interdisciplinaridade. São Paulo: Cortez Editora, 2010.

Reforma Psiquiátrica, tempos sombrios e resistência:

diálogos com o marxismo e o serviço social. Campinas, SP: Editora Papel Social, 2016. 